\title{
Understanding Experiences of Sexual Harms Facilitated through Dating and Hook Up Apps among Women and Girls
}

\author{
Elena Cama
}

\begin{abstract}
In recent years, the use of dating and hook up apps has become an increasingly socially acceptable and commonly used method of seeking romantic and sexual partners. This has seen a corresponding rise in media and crime reports of sexual harms facilitated through these services, including sexual harassment, unsolicited sexual imagery, and sexual assault. Emerging empirical research shows that experiences of sexual harms in this context are common and predominantly impact women and girls. The aim of this chapter is to examine the sociocultural and sexual norms that underpin online dating and which perpetuate a "rape culture" within which sexual harms become both possible and normalized. This chapter also considers how the discourses that minimize and legitimize sexual harms are encoded within the responses undertaken by dating and hook up apps to sexual harms. It is argued that together these norms and discourses may act to facilitate and/or prevent sexual harms, and may normalize and excuse these harms when they occur.
\end{abstract}

Keywords: Online dating; rape culture; sexual harms; technology-facilitated sexual violence; hook up apps; gender-based sexual violence

\section{Introduction}

The proliferation of mobile dating and hook up apps for seeking romantic and/or sexual partners has radically altered the way that people negotiate sex and intimacy. Although it is difficult to determine the number of people using dating and hook up apps, data indicate that use of these platforms is common.

The Emerald International Handbook of Technology-Facilitated Violence and Abuse, 333-350

Copyright $(9) 2021$ Elena Cama

Published by Emerald Publishing Limited. This chapter is published under the Creative

Commons Attribution (CC BY 4.0) licence. Anyone may reproduce, distribute, translate and create derivative works of these chapters (for both commercial and non-commercial purposes), subject to full attribution to the original publication and authors. The full terms of this licence may be seen at http://creativecommons.org/licences/by/4.0/legalcode.

doi:10.1108/978-1-83982-848-520211025 
Approximately $30 \%$ of US adults report that they have ever used a dating app or site (Pew Research Center, 2020). One of the most popular apps, Tinder, has approximately 57 million users worldwide, 10 million active daily users, and around 1.6 billion daily swipes (Iqbal, 2019; Smith, 2020).

Following Byron and Albury's (2018) work, "dating and hook up apps" in this chapter refers to mobile applications that offer opportunities for service users to seek dates, love, sex, or romance. "Hook up" refers to the increasingly normative practice among adults of engaging in sexual encounters (including, but not limited to, sexual intercourse) where there is no expectation of dating or forming a romantic relationship (Garcia, Reiber, Massey, \& Merriwether, 2012). While the term "hook up app" may primarily refer to users' motivations for seeking casual sexual encounters using mobile apps, in practice there are a wide range of reasons why people use these platforms, including socializing and friendship, relational ambitions, sex, ease of communication, validation of self-worth, self-esteem enhancement, and fun and entertainment (Bryant \& Sheldon, 2017; Sumter, Vandenbosch, \& Ligtenberg, 2017).

The focus in public health research on sexual health and other "risks" (e.g., sexual risk behaviors and sexually transmissible infections) in relation to dating and hook up app use has been criticized for failing to consider the broader affordances these apps offer for negotiating and engaging in sex and intimacy (Byron \& Albury, 2018). However, alongside the potential benefits of dating and hook up apps, it is also clear that these platforms have served as sites for the perpetration or facilitation of sexual harms, such as the sending of unsolicited or unwanted sexual imagery and contact-based sexual offenses. Although there is a broader literature base on people's experiences and the impacts of digital harms (Powell \& Henry, 2017, 2019), examination of the nature and impacts of harms within online dating remains understudied and warrants urgent attention.

In this chapter, I examine the sociocultural and sexual norms that underpin online dating, and which perpetuate the norms, values, and practices that underlie "rape culture." I discuss how these norms may be embedded within the responses undertaken by dating and hook up apps to sexual harms. Together these may act to facilitate and/or prevent sexual harms, as well as normalize and excuse these harms when they occur. I first briefly outline the literature on sexual harms perpetrated or facilitated via dating and hook up apps and websites, then turn to the sociocultural and sexual norms that underpin online dating and which perpetuate rape culture. This is followed by an examination of the ways in which these norms are embedded within dating and hook up app responses to sexual harms, and how these apps may facilitate and/or prevent sexual harms from occurring. While this chapter focuses on women's and girls' experiences of sexual harms, I end this chapter with a call to "queer" sexual violence by rejecting cis-sexist, heteronormative discourses of sexuality and gender which perpetuate rape culture, and embracing alternative narratives of experiences of sexual harms.

\section{Sexual Harms in Online Dating}

Online dating has its origins in personal ads placed in newspapers from the late 1600s (Lee, 2016). The first online dating website, Kiss.com, launched in 1994, 
and the first mobile app, Grindr, launched in 2009 (Jackson, 2018; Lee, 2016). Despite dating apps and websites being available for more than two decades, it is only more recently that researchers have begun to examine experiences of sexual harms in the context of modern dating platforms. In this chapter, "sexual harms" refer to a complex array of unwanted sexual behaviors that people may experience as harmful, including, but not limited to, those that are perpetrated or mediated via digital communications technologies. This approach is influenced by the work of feminist scholars who reject linear, hierarchical conceptualizations of harm and move instead toward continuum-based approaches to women's safety and experiences of sexual harms (Kelly, 1987, 1988, 2012; Stanko, 1985, 1990). This approach also recognizes the diverse range of harms that may be experienced and demonstrates how the categories that are typically used to define sexual harms are not discrete, but rather overlap in their nature and impacts (Kelly, 1987, 1988, 2012; Stanko, 1985, 1990).

Sexual harms in dating and hook up app contexts may include, but are by no means limited to, unwanted requests for sex, unwanted sexual comments, unsolicited sexual imagery or video, image-based sexual abuse, and contact-based harms. Sexual harms intersect with other identity markers and reinforce social asymmetries, such as race, class, sexuality, and disability. Thus, the term "sexual harms" may also include harms that are not necessarily "sexual" in nature, but which nevertheless reproduce gendered power relations (Kelly, 1988). More broadly, data indicate that experiences of sexual harms perpetrated or facilitated via digital communications technologies, commonly referred to as "technologyfacilitated sexual violence," are common (Powell \& Henry, 2017, 2019; Powell, Scott, Flynn, \& Henry, 2020). While both men and women experience these types of harms, research suggests that the nature and impacts of these experiences are gendered in nature. For example, men are more likely to be perpetrators of these harms, and women report greater impacts resulting from their experiences of these harms, such as feelings of distress and fears for their physical safety (Powell \& Henry, 2017, 2019).

Available research indicates that such experiences in the context of online dating are common. Gillett's (2019) doctoral research on women's experiences of everyday violence on Tinder is the most comprehensive examination of the range of sexual harms experienced by women and girls via dating platforms. Her findings highlight the continuum of experiences that women face, including unwanted requests for sex, attacks on gender and sexuality, unsolicited sexual images, possessive and controlling messages, and physical intrusions in face-toface interactions, including those that would meet legal definitions of sexual assault. To date, much of the available literature has focused on women's experiences of sexual harassment, including the receipt of unsolicited sexual images of men's genitals, popularly termed "dick pics" (e.g., Douglass, Wright, Davis, \& Lim, 2018; Shaw, 2016; Vitis \& Gilmour, 2016). Survey data suggest that this practice is common, with one US survey by Match.com finding that almost half of men reported sending a picture of their penis to a potential partner and nearly half of women reported receiving one without asking for it (Match, 2017). A survey of Australians aged 16-29 years found that among the 535 participants who had used a dating app in the previous year, $57 \%$ had experienced sexual harassment ${ }^{1}$ in this context (Douglass et al., 2018). 
There have also been reports of physical sexual harms facilitated through dating and hook up apps, such as in initial face-to-face meetings (National Crime Agency, 2016; Powell \& Henry, 2017; Rowse, Bolt, \& Gaya, 2020). Data from the UK National Crime Agency (2016) indicate that the number of serious sexual assaults initiated as a result of online dating increased sixfold between 2009 and 2014, with the majority of victims being female. Although there are no similar data on trends in Australia, some comparative work has found that $9 \%$ of Australian adults and $10 \%$ of UK adults had reported that they have had an unwanted sexual experience with someone they had met via a dating app or website (Powell \& Henry, 2017). Finally, survey data among 1,244 US women found that $31 \%$ had been sexually assaulted or raped by someone they had met through a dating website (Flynn, Cousins, \& Picciani, 2019).

\section{"The Cultural Scaffolding of Rape": How "Rape Culture" Shapes Our Understandings of Sexual Harms in Online Dating}

The concept of "rape culture" is a useful lens through which to examine sexual harms occurring in the context of online dating. The ways in which victimsurvivors understand and respond to their personal experiences of sexual harms are largely contingent upon the social, cultural, political, and temporal context within which these experiences occur (Kelly, Burton, \& Regan, 1996). Therefore, it is useful to examine the norms, values, and practices that underpin the context in which these harms occur, and that may be creating an environment within which sexual harms become both possible and tolerated. The term "rape culture" was first articulated by feminists in the 1970s and has experienced a resurgence in popularity in more recent years in the wake of various feminist movements calling out and challenging rape culture (e.g., the \#MeToo Movement). Rape culture refers to a "complex set of beliefs that encourages male sexual aggression and supports violence against women" (Buchwald, Fletcher, \& Roth, 2005, p. xi). Within this culture, "sexual violence against women is implicitly and explicitly condoned, excused, tolerated, and normalized" (Powell, 2015, p. 575), and these beliefs are embedded to varying degrees within language, sociocultural and political practices, laws, and institutions (Powell \& Henry, 2014). While rape culture arguably applies globally, there are differences in its manifestation in distinctive sociocultural, legal, political, and temporal contexts (Mendes, Ringrose, \& Keller, 2019), and this chapter largely focuses on conceptualizations and manifestations of the concept in the Global-North.

There are two connected features that help to foster a rape culture and create and sustain the conditions for sexual harms: (1) heteronormative discourses of sex and gender that normalize male sexual aggression and female passivity; and (2) rape myths and jokes, victim-blaming, the policing of women's bodies and behaviors, and other discourses that serve to minimize, legitimize, and excuse men's violence (Gavey, 2005; Keller, Mendes, \& Ringrose, 2016; Sills et al., 2016). Scholarship on rape culture critiques assumptions that sexual violence is perpetrated by deviant individuals and instead highlights the ways that these harms are 
linked to or enabled by everyday sociocultural norms, values, and practices (Gavey, 2005; Sills et al., 2016). These two interconnected features and how they manifest in dating and hook up apps will be discussed in turn below.

\section{Heteronormative Discourses of Sex and Gender}

Gavey (2005) has explored the ways that "everyday taken-for-granted normative forms of heterosexuality work as a cultural scaffolding for rape" (p. 2). She suggests that normative discourses of sex and gender set up the preconditions for sexual violence by providing implicit templates for heterosex that position women's sexuality (or rather, asexuality) as passive and men's sexuality as aggressive and in need of sexual release ("male sexual drive" discourse). These discourses produce cultural meanings of sex and desire, which differentially impact men and women. Such discourses can potentially have the effect of constraining or compromising women's choices in heterosexual relationships, such that women have limited agency to pursue their own desires as their actions are premised on either meeting or denying men's desires (i.e., acting as "gatekeepers" of sex; see Gavey, 2005).

In her work, Gavey (2005) presents examples of unwanted sexual encounters that women experience in the absence of the use of physical force. For example, in interviews, women described having unwanted sex with their male partners for the purposes of maintaining a heterosexual relationship due to feelings of obligation or pressure. This is not to suggest that these forms of heterosex are rape. Rather, the norms surrounding heterosex can produce ambiguity about whether interactions are consensual or nonconsensual, and arguably authorize, legitimize, and trivialize sexual encounters that are not always distinguishable from dominant, or indeed legal, understandings of "rape" (Fileborn, 2016). These norms result in what Gavey (2005) notes is a "complex gray area between what we might think of as mutually consenting sex, on the one hand, and rape or sexual coercion on the other" (p. 128). While the concept of a gray area has been subject to critique (Hardcastle cited by Sebag-Montefiore, 2020), it may better capture those experiences that do not constitute rape (according to both normative and legal definitions), but which may be harmful, such as receiving unsolicited sexual imagery (i.e., "dick pics") via dating and hook up apps.

Drawing from Gavey's (2005) work, the normative heterosexual scripts that underpin online dating (and indeed, dating more broadly) may help to set up the preconditions for sexual harms experienced by women and girls, as well as normalize and excuse it when it occurs. Culturally produced meanings of sex and desire may influence the motivations and practices of dating and hook up app use by heterosexual men and women. For example, men are more likely to use Tinder for seeking casual sex (Sumter et al., 2017), while women are more likely to use it to seek long-term relationships, friendship, or for validation (Ranzini \& Lutz, 2017).

Research indicates that women are much less likely to initiate conversations on Tinder compared to men but are more likely to receive messages (Timmermans \& Courtois, 2018). These practices potentially support discourses that position men 
as active pursuers of sex. On the other hand, women may be more selective in their choice of men on Tinder in order to avoid those only interested in sexual encounters (Timmermans \& Courtois, 2018). For example, some women indicate on their dating profiles that casual sex is not an option in an attempt to prevent unwanted sexual requests before they occur (Chan, 2018). Women may also be required to interpret and respond to men's indications about their desires for sex on these platforms (Chan, 2018). If men have expectations that women will place obstacles in the way of their sexual gratification as an indication of lack of consent (Cense, Bay-Cheng, \& van Dijk, 2019), these practices of filtering out male partners and proactively avoiding sex are demonstrative of discourses of heterosex that position women as gatekeepers of sex.

While creating the possibility for nonconsensual or coercive experiences to occur, these norms simultaneously result in many experiences being labeled as "just sex," as they do not fit within dominant rape scripts. Rape scripts refer to the template for how sexual violence is viewed to typically proceed, including beliefs about who experiences sexual violence, the relationship between the victim and the perpetrator, the use of a weapon, the steps that typically women should take in order to prevent an assault (such as explicit nonconsent, wearing modest clothing, and not drinking alcohol), and how victims should respond to or be affected by the experience (Ryan, 2011). Encounters that do not conform to these normative scripts are often not perceived as meeting the threshold for inclusion as a form of sexual violence. That our normative understandings of sexual violence are framed in dichotomous terms (either an experience is "rape" or it is "not rape," and "violence" or "not violence") (Hindes \& Fileborn, 2019) means that experiences that are ambiguous or fall somewhere in between (or outside) may be more often discounted. This is exemplified by sexual harms that include the use of violence in an otherwise consensual sexual encounter and those that are not characterized by the use of physical violence. For example, media reports refer to women's experiences of stealthing ${ }^{2}$ in face-to-face interactions with men they have met on dating and hook up apps, with some noting that victims may be uncertain about whether these experiences constitute "rape" in the absence of physical violence (e.g., Triple J Hack, 2017). As another example, while the sending of unsolicited "dick pics" - a practice commonly associated with dating and hook up apps - is not an act of physical violence, women nevertheless may feel "visually assaulted" after receiving them (Segran \& Truong, 2016). Therefore, given that normative understandings of violence tend to be limited to the use of physical force and the explicit expression of nonconsent, interactions which do not conform to these understandings may be dismissed and potentially normalized (Gillett, 2018).

\section{Discourses that Serve to Minimize, Legitimize, and Excuse Men's Violence}

In addition to the ways that everyday norms, actions, and values enable sexual violence, Gavey (2005) was interested in the ways that these attitudes and behaviors also serve to legitimate breaches of sexual boundaries when harms do occur. These include a complex interplay of victim-blaming, rape myths and 
jokes, and the regulation of women's bodies (e.g., slut-shaming ${ }^{3}$ ). Where a victim's experience does not play out according to the expected script, this experience may be dismissed (including by the victim) (Gillett, 2019), and the victim may be blamed for what happened. Because dating and hook up apps are used by some women for the purposes of seeking casual sex, their experiences of sexual harms may be dismissed as "just sex," and they may be blamed for actions perceived to have been taken which put them at risk. This could include blame for behaviors that are a normative part of using dating and hook up apps to meet prospective partners, such as consumption of alcohol in face-to-face interactions and engaging in casual sex.

Dating and hook up apps are sexualized spaces, often with explicit purposes of facilitating "hook ups," yet some women are condemned for using the platforms according to their intended function (Chan, 2018; Jane, 2017), reflecting the sexual double standard ${ }^{4}$ that continues to exist in dating contexts (Jane, 2017; Sales, 2015). Some women dismiss their own experiences of intrusive behaviors by arguing that men have different motivations for using the apps than they do (Gillett, 2019). For instance, heterosexual women explain that these experiences occur because men are using these apps for the purposes of casual sex (Gillett, 2019), with both heterosexual and queer women justifying these experiences as inextricable from using dating and hook up apps (Duguay, Burgess, \& Suzor, 2020; Gillett, 2019). These findings are illustrative of assumptions of men's urgent, uncontrollable sex drive, which women must manage, as well as the discourses that continue to perpetuate victim-blaming and minimize sexual harms. There is no research examining slut-shaming and victim-blaming for women who experience sexual harms facilitated or perpetrated via dating platforms. However, other researchers have pointed to slut-shaming as an expression of victim-blaming of women who engage in digitally-mediated sexualized practices, such as the sending of sexual or sexually suggestive images or videos (Shariff \& DeMartini, 2015).

The sexual harms experienced by women and girls in dating and hook up app contexts do not occur in isolation of the broader harms experienced by women and girls in public and private spaces. Some women report that they expect to experience these harms both due to the sexualized nature of the apps and because they have experienced these harms in other contexts (Gillett, 2019). While online dating may be governed by its own set of norms and values, these do not operate in isolation from the sociocultural template governing social and sexual relations in society more broadly (Fileborn, 2016; Gavey, 2005). Instead, these are contexts in which sexual interaction is both normative and acceptable and therefore present an "intensification of the higher-level scaffolds" whereby the performance of sexuality may be exaggerated (Fileborn, 2016, p. 122).

\section{Technological Constraints and Affordances of Dating and Hook Up Apps}

While some researchers have pointed out the potential for social media platforms to be used as spaces to challenge rape culture (Rentschler, 2014), very few 
researchers have explored the ways that platforms may perpetuate rape culture. In this section, I consider how rape culture, particularly the discourses that minimize and legitimize sexual harms, is encoded within the responses undertaken by dating and hook up apps to sexual harms. I also consider the opportunities afforded by these apps for women to prevent and respond to sexual harms.

Judy Wajcman's (2002) "technofeminist" framework "conceive[d] of a twoway mutually shaping relationship between gender and technology in which technology is both a source and consequence of gender relations and vice versa" (p. 356). Technology is a "socio-technical" issue; that is, it is shaped by the social relationships within which it is produced and used. Adopting Wajcman's framework, sociocultural norms and values are programmed into technologies like dating and hook up apps (Bivens \& Hoque, 2018) and these technologies are encoded with gendered meanings which shape both their design and use. For example, the enforcement of rigid binary gender identification (i.e., male or female) on the dating apps Tinder and Bumble demonstrates the ways that gendered meanings can be encoded within technology. These practices serve no technological function, but instead act to limit the ways users can authentically present their gender identities to others (MacLeod \& McArthur, 2018).

The sociocultural and sexual norms that help to foster a rape culture are embedded within institutions to varying degrees. For dating and hook up apps, discourses that act to minimize, legitimize, and excuse sexual harms are key examples of the manifestations of a rape culture. Despite the "strong stance" supposedly taken by many of the dating and hook up apps in relation to harassment and abuse, these platforms have been criticized for failing to take action to prevent and respond to sexual harms (Duguay et al., 2020; Flynn et al., 2019; Picciani, 2020; see also Henry \& Witt, this volume). For example, in 2017 Tinder introduced "Reactions" as an antiharassment tool for women users, consisting of a set of animated responses permitting them to virtually throw a martini or sarcastically eye roll at another user. Arguably, this tool places responsibility on women to counter harmful behavior. It blurs the boundaries between flirting and abuse, has no tangible consequences for perpetrators, and ultimately serves to normalize, minimize, and trivialize experiences of harms perpetrated via the platform (Davies, 2017; Duguay et al., 2020).

Few platforms undertake background screening of users, and those that do are monetarily incentivized via paid subscriptions (Flynn et al., 2019). The majority of perpetrators of contact-based sexual offenses facilitated via dating and hook apps have no prior criminal record (National Crime Agency, 2016), thus platforms may be limited in their ability to prevent sexual harms from occurring. Further, reporting tools on platforms can be obscure and nondescript (Duguay et al., 2020). Even where women have reported experiences of sexual assault to these platforms, many of these women report that the platforms do not even respond, let alone act on these reports (Picciani, 2020). The ease of creating dating and hook up app profiles means that users who are temporarily or permanently banned from using the platform can create alternative profiles through which to perpetrate harms. 
Social norms also influence the uptake, enforcement, and effectiveness of policies and the ways that users understand the culture of the platform. Perceptions of a "hook up culture" (Sales, 2015), or "culture of sexting," may result in users not reporting harmful behavior when it occurs (Duguay et al., 2020, p. 242) and dismissing these experiences as "just sex." The framing of platforms like Tinder in this way could also influence the way that users engage with the app and with other people, in the sense that its connection to casual sexual encounters carries expectations for users to engage in such conduct (Duguay et al., 2020; Gillett, 2019). One woman described the pressures of having sex with men she had met through the app, stating, "well I met him on Tinder, this is what they expect" (Gillett, 2019, p. 149). If women are reporting expectations of experiencing unwanted sexual attention as well as engaging in sexual encounters they would not otherwise want (Duguay et al., 2020; Gillett, 2019), these apps may facilitate those "gray area" interactions that can neither be considered consensual nor nonconsensual, but nonetheless are unwanted. Given that women's motivations for using apps are less likely to be focused on sexual gratification (Ranzini \& Lutz, 2017), the design and marketing of apps for "hook ups" primarily services male user motivations and so are encoded with the same heteronormative discourses that govern dating more broadly.

While potentially constraining women's movement within digital spaces, technologies may simultaneously afford various opportunities. Technology is neither inherently patriarchal nor inherently liberating for women, but rather leaves "space for women's agency in transforming technologies" (Wajcman, 2004, p. 7), such as by reinterpreting technologies for political organizing or creating new feminist communities. These platforms may also possess features that help prevent or respond to sexual harms. For instance, platforms have a range of policies, guidelines, and reporting tools aimed at regulating harmful behavior.

"Unmatching," blocking, and reporting users are options that can help users to respond to unwanted communications. In 2019, the app Bumble launched new software to automatically blur "dick pics" and other graphic images, enabling users to make a choice as to whether or not they wish to view the image, block the user, or report the user to the app (Holmes, 2019). Communication within dating and hook up apps is recorded, and apps may require user identification, both of which could be used to support reports of harmful behavior both to the platform and other authorities (Duguay, 2017). However, the extent of the uptake or effectiveness of these mechanisms has been debated (Duguay et al., 2020; Picciani, 2020). For example, queer women speculate that reports to Tinder are rare due to the nondescript nature of the reporting button, and do not appear to be either technologically or socially enforced in any case (Duguay et al., 2020). As Waldman (2019) notes in the context of queer dating apps, while platforms may have near identical policies toward unwanted sexual behaviors, the differences may lie in design and enforcement, with some platforms having more intuitive reporting tools and being more responsive than others.

An additional affordance of dating and hook up apps is the ability to undertake filtering processes and safety work with potential dates in online communications prior to meeting up face-to-face (Cama, 2019; Couch \& Liamputtong, 2008). 
For example, women report utilizing a range of filtering and safety strategies when meeting someone from a dating or hook up app, including checking social media pages, meeting in a neutral public place, telling other people about the date (e.g., location), and having an exit strategy in case the date does not go well (Cama, 2019). However, these strategies place the burden for mitigating the risk of experiencing harm on women. The relative anonymity afforded by these apps may simultaneously provide opportunities for the perpetration of harmful behavior, while also providing women with opportunities to resist these harms. For example, women may feel emboldened to resist, reject, or call out men's sexist comments and unwanted requests for sex, as they may not have the same concerns for retaliation and physical safety that they would otherwise have in a face-to-face interaction (Dhillon \& Bakaya, 2014).

While dating and hook up apps may act as sites for the perpetration or facilitation of a range of sexual harms, they may also be used to subvert the same heteronormative discourses that help to perpetuate these harms. For example, some women use these platforms to disrupt discourses that assume women's supposed (a)sexuality and passive role in sex (Chan, 2018). For queer women, digital spaces may connect them with the LGBTQI+ community and help them to develop a sense of identity, helping to counter the negative effects of stigma and discrimination (Craig \& McInroy, 2014). The dating app Dattch, later renamed Her, was developed for women who are attracted to women, under the assumption that the rapid hook up affordances of apps like Grindr and Tinder do not work for queer women (Murray \& Ankerson, 2016). The dating app Bumble was founded with the stated aim of subverting the heteronormative gender roles and sexual scripts in modern dating by ensuring that women always make the first contact with prospective male partners (Bivens \& Hoque, 2018). However, Bivens and Hoque (2018) suggest that the norm that men should ask women out on a date reasserts itself after the initial contact, indicating that the extent to which these design practices can achieve their stated feminist goals is questionable (p. 450). Finally, feminist activists are co-opting other social media platforms to resist, reject, and call out men's perpetration of sexual harms via dating and hook up apps and in-person interactions (e.g., Bye Felipe, Tinder Nightmares). Not only do these act as a consciousness-raising tool in relation to gendered forms of violence and inequality, they also act as sites for people seeking social support following their own experiences of these harms.

\section{"Queering" Sexual Violence: Toward an Intersectional Understanding of Sexual Harms}

Research on sexual violence largely focuses on the perpetration of cisgender men's violence against cisgender women, privileging the voices of White, able-bodied, middle-class women who experience sexual harms. Such a focus erases and silences the experiences of people whose experience of violence is multilayered on the basis of a combination of factors, including gender, sexuality, race, and/or disability (Hackworth, 2018). Ethnically diverse people, and gender and sexuality diverse people, are significantly more likely to experience digitally-mediated 
sexual harms, including harassment based on their gender and/or sexuality (Powell, Scott, Flynn, \& Henry, 2020; Powell, Scott, \& Henry, 2020), and this applies in the context of dating and hook up apps and websites (Albury et al., 2019; Douglass et al., 2018). Same-sex attracted people report concerns about physical safety and nonconsensual experiences with people they have met online (Albury \& Byron, 2016; Bauermeister, Giguere, Carballo-Diéguez, Ventuneac, \& Eisenberg, 2010; Corriero \& Tong, 2016). Further, research suggests that there are high rates of experiences of nonconsensual distribution of sexual images among gay and bisexual men (Waldman, 2019; see also Dietzel, this volume). Much of the available research fails to capture the nuances of sexual harms experienced by people with other marginalized identities (Hackworth, 2018; Patterson, 2016). This chapter has thus far been predominantly focused on cisgender men's perpetration of harms against cisgender women. However, I will briefly note here the ways that rape culture harms those whose identities are situated outside heteronormative identities and whose experiences do not necessarily comply with "typical" rape scripts.

The dominant discourses of heterosex and sexual harms also function in specific ways to frame discourses of queer sexuality and violence (Mortimer, Powell, $\&$ Sandy, 2019). This acts to silence and render invisible the experiences of people who do not occupy heteronormative identities (Serisier, 2007). If the experiences of sexual harms among queer communities, people of culturally and linguistically diverse backgrounds, people living with disabilities, and other marginalized identities continue to be silenced, this perpetuates the myths and stereotypes that contribute to and perpetuate a rape culture. Mortimer et al.'s (2019) work highlights that heteronormative ideas about sex inform "typical" rape scripts, and assume the involvement of an "active" aggressive male against a "passive" victimized woman. This excludes the experiences of gender and sexuality diverse people and may restrict their capacity to access and identify with the language and concepts required to understand and articulate their experiences.

Heteronormative discourses relating to men's sex drive similarly result in sexual coercion among gay men being regarded as "unthinkable" or "oxymoronic" (Braun, Schmidt, Gavey, \& Fenaughty, 2009, p. 337). For example, as one gay male describes of unwanted experiences on dating apps, "gay male guys are, you know, everybody thinks that we always want sex" (Dietzel, this volume). In the context of dating and hook up app use, these discourses can result in gender and sexuality diverse people not identifying harmful experiences as constituting violence (Girshick, 2002); instead, rape culture positions these experiences as "just sex" (Gavey, 2005; see also Dietzel, this volume). As one participant in Dietzel's (this volume) research notes:

It's this weird fucked-up dynamic of when you are going through with something when you don't really want to. ... In a sense, you are consenting, because you're like, "I am going forward. No one is holding a gun to my head or whatever." But it's a sort of social obligation gun-being-held-to-my-head and I feel like I'm doing something that I don't actually want to do. (p. 359) 
Patterson (2016) encourages a shift to "queer" sexual violence, in the political sense of the term "queer." This involves a rejection of mainstream ideas on sexuality and gender, to move us beyond dominant narratives around sexual violence, and to examine the stories of those whose survivorhood does not follow "normal" or predictable narratives or trajectories of harm. Patterson (2016) states that "until we... acknowledge that all genders experience and perpetrate violence, we will be working on only a small piece of the larger puzzle" (p. 11). The lack of a strong body of conceptual work on alternative narratives of sexual harms, including those experienced by gender and sexuality diverse people, presents an opportunity for future research on dating and hook up apps to embrace alternative voices and stories within the survivor movement. This will necessarily include examination of sexual harms in all their "complexities and 'messiness"" (Fileborn \& Phillips, 2019, p. 100), opening up the possibilities for our understandings of these harms and including those experiences that are minimized and normalized within popular culture, and which not all people necessarily experience as harmful (Vera-Gray, 2016). As just one example, "dick pics" may be a normative part of the culture of dating online for many gay and bisexual men (Alvear, 2017; Dietzel, this volume). Thus, while we need to recognize the ways in which sharing images may feature as a wanted exchange for some, we must also remain sensitive to the ways that these norms, including assumptions about men's sexuality, may be used to dismiss or trivialize the perspectives of those who experience receiving such images as distressing and harmful.

\section{Conclusion}

This chapter has attempted to contribute to a more nuanced understanding of the broad range of "sexual harms" perpetrated or facilitated via dating and hook up apps. The values and norms which underpin this highly sexualized context represent an intensification of the broader social template and can act to minimize, excuse, and condone men's violence against women. These norms are embedded within the design of the apps themselves, with many apps designed and marketed for the purposes of casual sex. Given that women commonly report using these apps for purposes other than casual sex, the sociocultural and sexual norms embedded within apps may constrain and limit the choices that women have to pursue their own desires. Many of the harms experienced in dating and hook up app contexts occur online or in the absence of physical force, and therefore these norms may also act to legitimize and dismiss harmful experiences as "just sex," where they do not fit within dominant rape narratives.

Further, limited reporting options and a lack of action taken by platforms in responding to sexual harms are illustrative of a culture within which harms are tolerated and excused. The introduction of features by platforms, which place the burden on users to respond to harmful experiences and trivializes experiences where physical forms of harm are absent, is particularly demonstrative of this point. While limiting the ability of women and girls to safely negotiate intimacy via these platforms, these apps may potentially afford women and girls with 
opportunities to resist and subvert heteronormative discourses and sexual harms. By "queering" understandings of dating app usage and sexual harms, we may be able to more meaningfully explore how these discourses feature in and are potentially differently mobilized and navigated in nonheterosexual dating cultures.

\section{Notes}

1. Sexual harassment was broadly defined as "any unwanted sexual attention/ harassment including cat-calling, comments on appearance, getting 'hit on', touching, staring, receiving sexual pictures/texts, stalking or any other form of unwanted attention from strangers or people you know" (Douglass et al., 2018, p. 362).

2. "Stealthing" refers to the nonconsensual removal of a condom during what is an otherwise consensual sexual encounter (Chesser \& Zahra, 2019).

3. Slut-shaming refers to "the act of criticizing women or girls for their real or presumed sexuality or sexual activity, as well as for looking or behaving in ways that are believed to transgress sexual norms" (Karaian, 2014, p. 296).

4. The term "sexual double standard" describes how men and women's engagement in sexual behaviors are held to different standards - women are expected to engage in digitally-mediated sexual practices by men, yet are morally condemned and slutshamed when they do, while men are not subject to the same judgements (Ringrose, Harvey, Gill, \& Livingstone, 2013).

\section{References}

Albury, K., \& Byron, P. (2016). Safe on my phone? Same-sex attracted young people's negotiations of intimacy, visibility, and risk on digital hook-up apps. Social Media + Society, 2(4), 1-10. doi:10.1177/2056305116672887

Albury, K., Byron, P., McCosker, A., Pym, T., Walshe, J., Race, K., \& Dietzel, C. (2019). Safety, risk and wellbeing on dating apps: Final report. Melbourne, VIC: Swinburne University of Technology.

Alvear, M. (2017). 83 percent of gay men have sent a dick pic on dating apps, says survey. Huff Post. Retrieved from https://huffpost.com

Bauermeister, J. A., Giguere, R., Carballo-Diéguez, A., Ventuneac, A., \& Eisenberg, A. (2010). Perceived risks and protective strategies employed by young men who have sex with men (YMSM) when seeking online sexual partners. Journal of Health Communication, 15(6), 679-690. doi:10.1080/10810730.2010.499597

Bivens, R., \& Hoque, A. (2018). Programming sex, gender, and sexuality: Infrastructural failures in 'feminist' dating app Bumble. Canadian Journal of Communication, 43(3), 441-459. doi:10.22230/cjc.2019v44n3a3375

Braun, V., Schmidt, J., Gavey, N., \& Fenaughty, J. (2009). Sexual coercion among gay and bisexual men in Aotearoa/New Zealand. Journal of Homosexuality, 56(3), 336-360. doi:10.1080/00918360902728764

Bryant, K., \& Sheldon, P. (2017). Cyber dating in the age of mobile apps: Understanding motives, attitudes, and characteristics of users. American Communication Journal, 19(2), 1-15. Retrieved from https://pdfs.semanticscholar.org/c32e/ d8d871edc872b7793891c2bf9e1184421080.pdf 
Buchwald, E., Fletcher, P., \& Roth, M. (2005). Transforming a rape culture (revised). Minneapolis, MN: Milkweed Editions.

Byron, P., \& Albury, K. (2018). "There are literally no rules when it comes to these things": Ethical practice and the use of dating/hook-up apps. In A. S. Dobson, B. Robards, \& N. Carah (Eds.), Digital intimate publics and social media (pp. 213-229). Cham: Palgrave Macmillan.

Cama, E. (2019, December). The nature and impacts of technology-facilitated sexual violence in online dating. Paper Presented at the 32nd Annual Australian and New Zealand Society of Criminology Conference, Perth, WA.

Cense, M., Bay-Cheng, L., \& van Dijk, L. (2019). 'Do I score points if I say "no"?': Negotiating sexual boundaries in a changing normative landscape. Journal of Gender-Based Violence, 2(2), 277-291. doi:10.1332/239868018x15266373560443

Chan, L. S. (2018). Liberating or disciplining? A technofeminist analysis of the use of dating apps among women in urban China. Communication, Culture and Critique, 11(2), 298-314. doi:10.1093/ccc/tcy004

Chesser, B., \& Zahra, A. (2019). Stealthing: A criminal offence?. Current Issues in Criminal Justice, 31(2), 217-235. doi:10.1080/10345329.2019.1604474

Corriero, E. F., \& Tong, S. T. (2016). Managing uncertainty in mobile dating applications: Goals, concerns of use, and information seeking in Grindr. Mobile Media and Communication, 4(1), 121-141. doi:10.1177/2050157915614872

Couch, D., \& Liamputtong, P. (2008). Online dating and mating: The use of the internet to meet sexual partners. Qualitative Health Research, 18(2), 268-279. doi: $10.1177 / 1049732307312832$

Craig, S. L., \& McInroy, L. (2014). You can form a part of yourself online: The influence of new media on identity development and coming out for LGBTQ youth. Journal of Gay \& Lesbian Mental Health, 18(1), 95-109. doi:10.1080/ 19359705.2013.777007

Davies, H. J. (2017, October 9). Does Tinder's Menprovement initiative do enough to protect women?. The Guardian. Retrieved from https://www.theguardian.com

Dhillon, M., \& Bakaya, S. (2014). Street harassment: A qualitative study of the experiences of young women in Delhi. SAGE Open, 4(3), 1-11. doi:10.1177/ 2158244014543786

Douglass, C. H., Wright, C. J. C., Davis, A. C., \& Lim, M. S. C. (2018). Correlates of in-person and technology-facilitated sexual harassment from an online survey among young Australians. Sexual Health, 15(4), 361-365. doi:10.1071/SH17208

Duguay, S. (2017). Dressing up Tinderella: Interrogating authenticity claims on the mobile dating app Tinder. Information, Communication \& Society, 20(3), 351-367. doi:10.1080/1369118X.2016.1168471

Duguay, S., Burgess, J., \& Suzor, N. (2020). Queer women's experiences of patchwork platform governance on Tinder, Instagram, and Vine. Convergence, 26, 237-252. doi:10.1177/1354856518781530

Fileborn, B. (2016). Reclaiming the night-time economy: Unwanted sexual attention in pubs and clubs. London: Palgrave Macmillan.

Fileborn, B., \& Phillips, N. (2019). From 'me too' to 'too far'? Contesting the boundaries of sexual violence in contemporary activism. In B. Fileborn \& R. Loney-Howes (Eds.), \#MeToo and the politics of social change (pp. 99-115). Cham: Palgrave Macmillan. 
Flynn, H., Cousins, K., \& Picciani, E. N. (2019). Tinder lets known sex offenders use the app. It's not the only one. ProPublica. Retrieved from https://www.propublica.org

Garcia, J. R., Reiber, C., Massey, S. G., \& Merriwether, A. M. (2012). Sexual hookup culture: A review. Review of General Psychology, 16(2), 161-176. doi:10.1037/ a 0027911

Gavey, N. (2005). Just sex? The cultural scaffolding of rape. East Sussex: Routledge.

Gillett, R. (2018). Intimate intrusions online: Studying the normalisation of abuse in dating apps. Women's Studies International Forum, 69, 212-219. doi:10.1016/ j.wsif.2018.04.005

Gillett, R. (2019). Everyday violence: Women's experiences of intimate intrusions on Tinder. Brisbane: Queensland University of Technology.

Girshick, L. B. (2002). No sugar, no spice: Reflections on research on woman-towoman sexual violence. Violence Against Women, 8(12), 1500-1520. doi:10.1177/ 107780102237967

Hackworth, L. (2018). Limitations of "just gender": The need for an intersectional reframing of online harassment discourse and research. In J. R. Vickery, \& T. Everbach (Eds.), Mediating misogyny: Gender, technology and harassment (pp. 51-70). Cham: Palgrave Macmillan.

Hindes, S., \& Fileborn, B. (2019). "Girl power gone wrong": \#MeToo, Aziz Ansari, and media reporting of (grey area) sexual violence. Feminist Media Studies, 20, 1-18. doi:10.1080/14680777.2019.1606843

Holmes, A. R. (2019). Bumble to launch software that blurs dick pics and graphic images. Metro. Retrieved from https://metro.co.uk

Iqbal, M. (2019). Tinder revenue and usage statistics (2018). Retrieved from https:// www.businessofapps.com/data/tinder-statistics/

Jackson, K. C. (2018). A brief history of online dating. Retrieved from https://swipelife.tinder.com/post/a-brief-history-of-online-dating

Jane, E. A. (2017). Feminist digilante responses to a slut-shaming on Facebook. Social Media + Society, 3(2), 1-10. doi:10.1177/2056305117705996

Karaian, L. (2014). Policing 'sexting': Responsibilization, respectability and sexual subjectivity in child protection/crime prevention responses to teenagers' digital sexual expression. Theoretical Criminology, 18(3), 282-299. doi:10.1177/1362480613504331

Keller, J., Mendes, K., \& Ringrose, J. (2016). Speaking 'unspeakable things:' documenting digital feminist responses to rape culture. Journal of Gender Studies, 27, 1-15. doi:10.1080/09589236.2016.1211511

Kelly, L. (1987). The continuum of sexual violence. In J. Hanmer \& M. Maynard (Eds.), Women, violence and social control (pp. 46-60). London: Macmillan Press.

Kelly, L. (1988). Surviving sexual violence. Minneapolis, MN: University of Minnesota Press.

Kelly, L. (2012). Standing the test of time? Reflections on the concept of the continuum of sexual violence. In J. M. Brown \& S. L. Walklate (Eds.), Handbook of sexual violence (Vol. xvii-xxvi). Oxon: Routledge.

Kelly, L., Burton, S., \& Regan, L. (1996). Beyond victim or survivor: Sexual violence, identity and feminist theory and practice. In L. Adkins \& V. Merchant (Eds.), Sexualizing the social: Power and the organization of sexuality (pp. 77-101). New York, NY: St Martin's Press. 
Lee, S. (2016). The history of online dating from 1695 to now. Huff Post. Retrieved from https://www.huffpost.com

MacLeod, C., \& McArthur, V. (2018). The construction of gender in dating apps: An interface analysis of Tinder and Bumble. Feminist Media Studies. doi:10.1080/ 14680777.2018.1494618

Match. (2017). Singles in America. Retrieved from https://www.singlesinamerica.com/ $2017 /$

Mendes, K., Ringrose, J., \& Keller, J. (2019). Digital feminist activism: Girls and women fight back against rape culture. New York, NY: Oxford University Press.

Mortimer, S., Powell, A., \& Sandy, L. (2019). 'Typical scripts' and their silences: Exploring myths about sexual violence and LGBTQ people from the perspectives of support workers. Current Issues in Criminal Justice, 31(3), 333-348. doi:10.1080/ 10345329.2019.1639287

Murray, S., \& Ankerson, M. S. (2016). Lez takes time: Designing lesbian contact in geosocial networking apps. Critical Studies in Media Communication, 33(1), 53-69. doi:10.1080/15295036.2015.1133921

National Crime Agency. (2016). Emerging new threat in online dating: Initial trends in internet dating-initiated serious sexual assaults. London: National Crime Agency.

Patterson, J. (Ed.). (2016). Queering sexual violence. Riverdale, NY: Riverdale Avenue Books.

Pew Research Center. (2020). The virtues and downsides of online dating. Retrieved from https://www.pewresearch.org/internet/wp-content/uploads/sites/9/2020/02/PI_ 2020.02.06_online-dating_REPORT.pdf

Picciani, E. N. (2020). He sexually assaulted her after they met on Bumble. Then she saw him on Tinder. Then Hinge. ProPublica. Retrieved from https://www.propublica.org

Powell, A. (2015). Seeking rape justice: Formal and informal responses to sexual violence through technosocial counterpublics. Theoretical Criminology, 19(4), 1-35. doi:10.1177/1362480615576271

Powell, A., \& Henry, N. (2014). Framing sexual violence prevention: What does it mean to challenge a rape culture?. In N. Henry \& A. Powell (Eds.), Preventing sexual violence: Interdisciplinary approaches to overcoming a rape culture (pp. 1-21). London: Palgrave Macmillan.

Powell, A., \& Henry, N. (2017). Sexual violence in a digital age. London: Palgrave Macmillan.

Powell, A., \& Henry, N. (2019). Technology-facilitated sexual violence victimization: Results from an online survey of Australian adults. Journal of Interpersonal Violence, 34, 3637-3665. doi:10.1177/0886260516672055

Powell, A., Scott, A. J., \& Henry, N. (2020). Digital harassment and abuse: Experiences of sexuality and gender minority adults. European Journal of Criminology, 17(2), 199-223. doi:10.1177/1477370818788006

Powell, A., Scott, A. J., Flynn, A., \& Henry, N. (2020). Image-based sexual abuse: An international study of victims and perpetrators. Melbourne: RMIT University. Retrieved from https://www.researchgate.net/publication/339488012_Image-based_ sexual_abuse_An_international_study_of_victims_and_perpetrators

Ranzini, G., \& Lutz, C. (2017). Love at first swipe? Explaining Tinder selfpresentation and motives. Mobile Media \& Communication, 5(1), 80-101. doi: $10.1177 / 2050157916664559$

Rentschler, C. (2014). Rape culture and the feminist politics of social media. Girlhood Studies. 7(1), 65-82. doi:10.3167/ghs.2014.070106 
Ringrose, J., Harvey, L., Gill, R., \& Livingstone, S. (2013). Teen girls, sexual double standards and 'sexting': Gendered value in digital image exchange. Feminist Theory, 14(3), 305-323. doi:10.1177/1464700113499853

Rowse, J., Bolt, C., \& Gaya, S. (2020). Swipe right: The emergence of dating-app facilitated sexual assault. A descriptive retrospective audit of forensic examination caseload in an Australian metropolitan service. Forensic Science, Medicine and Pathology, 16, 71-77. doi:10.1007/s12024-019-00201-7

Ryan, K. M. (2011). The relationship between rape myths and sexual scripts: The social construction of rape. Sex Roles, 65(11), 774-782. doi:10.1007/s11199-0110033-2

Sales, N. J. (2015). Tinder and the dawn of the "dating apocalypse." Vanity Fair. Retrieved from https://www.vanityfair.com

Sebag-Montefiore, C. (2020). Sophie hardcastle on finding her voice after sexual violence: "We do scream deep down." The Guardian. Retrieved from https:// www.theguardian.com

Segran, E., \& Truong, K. (2016). Why do men send dick pics - 10 men explain. Refinery 29. Retrieved from https://www.refinery29.com

Serisier, T. (2007). Speaking out against rape: Feminist (her)stories and anti-rape politics. Lilith: A Feminist History Journal, 16, 84-95. Retrieved from https:// pure.qub.ac.uk/en/publications/speaking-out-against-rape-feminist-herstories-andanti-rape-polit

Shariff, S., \& DeMartini, A. (2015). Defining the legal lines: eGirls and intimate images. In J. Bailey \& V. Steeves (Eds.), eGirls, eCitizens (pp. 281-305). Ottawa, ON: The University of Ottawa Press.

Shaw, F. (2016). "Bitch I said hi": The Bye Felipe campaign and discursive activism in mobile dating apps. Social Media + Society, 2(4), 1-10. doi:10.1177/20563051166 72889

Sills, S., Pickens, C., Beach, K., Jones, L., Calder-Dawe, O., Benton-Greig, P., \& Gavey, N. (2016). Rape culture and social media: Young critics and a feminist counterpublic. Feminist Media Studies, 16(6), 935-951. doi:10.1080/14680777. 2015.1137962

Smith, C. (2020). 50 interesting Tinder statistics and facts | by the numbers. Retrieved from https://expandedramblings.com/index.php/tinder-statistics/

Stanko, E. (1985). Intimate intrusions: Women's experience of male violence. London: Routledge \& Kegan Paul Ltd.

Stanko, E. (1990). Everyday violence: How women and men experience sexual and physical danger. London: Pandora Press.

Sumter, S. R., Vandenbosch, L., \& Ligtenberg, L. (2017). Love me Tinder: Untangling emerging adults' motivations for using the dating application Tinder. Telematics and Informatics, 34(1), 67-78. doi:10.1016/j.tele.2016.04.009

Timmermans, E., \& Courtois, C. (2018). From swiping to casual sex and/or committed relationships: Exploring the experiences of Tinder users. The Information Society, 34(2), 59-70. doi:10.1080/01972243.2017.1414093

Triple J Hack. (2017). Manipulation, abuse, deceit: How I learnt about 'stealthing' from a Tinder date. $A B C$. Retrieved from https://www.abc.net.au/triplej/programs/hack/ manipulation-abuse-deceitl-how-i-learnt-about-stealthing/8480696

Vera-Gray, F. (2016). Men's stranger intrusions: Rethinking street harassment. Women's Studies International Forum, 58, 9-17. doi:10.1016/j.wsif.2016.04.001 
Vitis, L., \& Gilmour, F. (2016). Dick pics on blast: A woman's resistance to online sexual harassment using humour, art and Instagram. Crime, Media, Culture, 13(3), 335-355. doi:10.1177/1741659016652445

Wajcman, J. (2002). Addressing technological change: The challenge to social theory. Current Sociology, 50(3), 347-363. doi:10.1177/0011392102050003004

Wajcman, J. (2004). Technofeminism. Cambridge: Polity Press.

Waldman, A. E. (2019). Law, privacy, and online dating: "Revenge porn" in gay online communities. Law \& Social Inquiry, 44(4), 987-1018. doi:10.1017/1si.2018.29 